\title{
Limited usefulness of CA125 measurement in the management of Hodgkin's and non-Hodgkin's lymphoma
}

\author{
Christophe Bonnet ${ }^{1 *}, Y_{v e s}$ Beguin ${ }^{1 *}{ }^{\dagger}$, Marie-France Fassotte ${ }^{1}$, Laurence Seidel ${ }^{2}$, Françoise Luyckx ${ }^{3}$, \\ Georges Fillet ${ }^{1}$
}

${ }^{1}$ Departments of Hematology; ${ }^{2}$ Biostatistics; ${ }^{3}$ Clinical Chemistry, University of Liege, CHU - Sart Tilman, Liège, Belgium

\begin{abstract}
Background: Several papers have reported an association of high CA125 serum levels with advanced nonHodgkin's lymphoma (NHL) as well as a relationship between high CA125 values and poor outcome. Patients and methods: Ninety-nine patients with NHL or Hodgkin's disease (HD) underwent serum CA125 assessment at diagnosis. Gender, age, presence of B symptoms, performance status (PS), histology, sites of tumor involvement, presence of effusion, clinical stage, age-adjusted International Prognostic Index, C-reactive protein (CRP), Hb, lactate deshydrogenase (LDH) and $\beta 2$-microglobulin were evaluated for their association with serum CA125 levels. The impact of CA125 levels and other features on overall (OS) and progression-free (PFS) survival was also assessed. Results: CA125 serum levels were elevated in $34 \%$ of the patients, including $19 \%$ of patients with aggressive $\mathrm{NHL}, 45 \%$ of patients with indolent $\mathrm{NHL}$, and $29 \%$ of patients with HD. Univariate analyses showed that CA125 levels correlated with poor PS, the presence of B symptoms, advanced clinical stage, abdominal, bone marrow or mediastinal involvement, presence of effusions, high aalPI, low Hb levels and high CRP, LDH or $\beta 2$-microglobulin levels. In multivariate analysis, bone marrow involvement, the presence of effusions, and high aalPI were all associated with high CA125 serum levels. In univariate analyses, OS and PFS were affected by age (PFS only), poor PS, B symptoms, advanced clinical stage, bone marrow or abdominal involvement (PFS only), high aalPI, low $\mathrm{Hb}$, high CRP or $\beta 2$-microglobulin levels. OS and PFS were not different in patients with normal or elevated CA125 levels. Multivariate analyses showed significantly inferior OS and PFS in patients with high $\beta 2$-microglobulin but no influence of CA125. Conclusion: While CA125 serum level correlates significantly with a number of features associated with more aggressive disease, it does not enhance the performance of standard prognostic markers in the management of patients with NHL or HD.
\end{abstract}

Key words CA125; non-Hodgkin's lymphoma; Hodgkin's disease

Correspondence $\operatorname{Dr}$ C. Bonnet, Department of Hematology, University of Liege, CHU - Sart Tilman, Liège, Belgium. Tel: +32-4366.72.01; Fax +32-4-366.88.55; e-mail: cbonnet@ulg.ac.be

${ }^{*} \mathrm{C}$. Bonnet and $\mathrm{Y}$. Beguin contributed equally to this work.

$\dagger$ Y. Beguin is Research Director of the National Fund for Scientific Research, (FNRS, Belgium).

Accepted for publication 7 February 2007

doi:10.1111/j.1600-0609.2007.00843.x

CA125 is a glycoprotein (200 KD) expressed by epithelial ovarian tumors. CA125 levels in serum can be used to follow response to treatment in patients with ovarian carcinoma. However, elevated CA125 serum levels have also been reported in other gynecological pathologies, some non-gynecological malignant disorders and even in benign pleural or abdominal effusions $(1,2)$.
Since 1995, several papers reported the association of high CA125 serum levels with non-Hodgkin's lymphoma (NHL). With the exception of age, most of the IPI's (3) factors were found to be associated with high CA125 levels in six prospective or retrospective studies $(1,2,4-7)$. Bulky disease and/or high tumor burden were reported to be associated with high CA125 levels in seven studies $(1,2,4$, 
5, 7-9). Produced by mesothelial cells, this biological marker appeared to be strongly correlated with the presence of effusions and abdominal involvement. The association with B symptoms or bone marrow involvement has also been described in some studies $(1,4,6,7,9,10)$. Finally, CA125 serum level at diagnosis has been reported to be a new prognostic factor $(1,4,6,7)$ and it has been proposed to incorporate it in the current prognostic index. On the other hand, CA125 levels have rarely been examined in patients with Hodgkin's disease (HD).

In this study, we analyzed the clinical characteristics associated with elevated CA125 levels at diagnosis and examined whether abnormal CA125 serum levels were associated with altered overall survival (OS) or progressive-free survival (PFS) in 99 patients with HD or NHL.

\section{Patients and methods}

\section{Patients}

Between July 2000 and January 2005, 99 consecutive patients hospitalized in our center with newly diagnosed NHL or HD underwent serum CA125 assessment at diagnosis. Their characteristics are detailed in Table 1. Tumors were classified according to the REAL classification (11). The extent of the disease was evaluated by means of physical examination, computed tomography of the chest, abdomen and pelvis, total body PET scanner, bone marrow biopsy, as well as other investigations depending on clinical symptoms and signs. Staging was defined on the basis of the Ann Arbor classification (12). Performance status was assessed according to the Eastern Cooperative Oncology Group scale.

\section{Laboratory analyses}

All laboratory analyses were determined on fresh samples collected on the same day at diagnosis. Serum CA125 was measured on a Modular E170 autoanalyser by Electrochemiluminescence Immunoassay (Roche, Basel, Switzerland) with a measuring range of $0.6-5000 \mathrm{UI} / \mathrm{mL}$ (reference range $0-35 \mathrm{UI} / \mathrm{mL}$ ). Serum $\beta_{2}$-microglobulin (Radioimmunoassay; Immunotech, Prague, Czech Republic, reference range 1-2.5 mg/L), serum lactate deshydrogenase (LDH) (enzymatic UV-assay; Roche, reference range 240-480 UI/L), hemoglobin (Cyanmethemoglobin method; Bayer Technicon, Tarrytown, NY, USA) and Creactive protein (CRP) (Immunoturbidimetric assay; Roche) were also obtained in all patients.

\section{Statistical analyses}

Results were expressed as means \pm standard deviations, medians and ranges for continuous variables and as percentages for categorical variables. Biological parameters were log-transformed whenever appropriate. Patients with normal or elevated CA125 levels were compared by logistic regression for each variable separately but also for all variables combined into a backward selection procedure (13). OS and PFS were evaluated by Cox regression models with application of a backward selection procedure. Multivariate analyses were carried out by adjusting for the histological group and in the case of OS and PFS for CA125 levels. Results were considered to be significant at the $5 \%$ level $(P<0.05)$. Data analysis was carried out using SAS 9.1 for Windows (SAS Institute, Cary, NC, USA) statistical package.

\section{Results}

Characteristics of the patients (demography, clinical and biological parameters) are listed in Table 1 for the total population and within each histological group. There were 27 patients with indolent NHL (Lymphocytic lymphoma $n=1$, follicular lymphoma $n=15$, malt lymphoma $n=$ 6 , unclassified $n=5$ ), 51 with aggressive NHL (Diffuse large B cell lymphoma $n=39$, mantle cell lymphoma $n=$ 6 , anaplastic large cell lymphoma $n=2$, periperal T-cell lymphoma $n=3$, Burkitt's lymphoma $n=1$ ) and 21 patients with HD (Nodular lymphocyte-predominant HD $n=3$, nodular sclerosis $\mathrm{HD} n=16$, mixed cellularity HD $n=1$, unclassified HD $n=1)$. There were $42(42 \%)$ women and $57(58 \%)$ men, mean age was $57 \pm 18 \mathrm{yr}$ (median $58 \mathrm{yr}$, range 15-88 yr). Among patients, 17\% had poor performance status, $22 \%$ presented B symptoms, $58 \%$ had an advanced clinical stage, 50\% abdominal, $40 \%$ mediastinal and $28 \%$ bone marrow involvement, and $14 \%$ an effusion. The aaIPI was $\geq 1$ in $37 \%$ of the patients.

CA125 serum level was $105 \pm 368 \mathrm{UI} / \mathrm{mL}$ and was elevated in 34 patients $(34 \%)$. Proportions of patients with elevated CA125 serum levels did not significantly differ among the three histological groups (indolent NHL: $19 \%$, aggressive NHL: $45 \%$, HD: $29 \% ; P=$ $0.059)$. There was also no significant difference for age $(P=0.46)$ and sex $(P=0.86)$. Patients with elevated CA125 serum levels had more frequently poor performance status $(37 \%$ vs. $8 \%, P=0.0015)$, B symptoms (42\% vs. $11 \%, P=0.0009)$, advanced clinical stage (88\% vs. $42 \%, P<0.0001$ ), abdominal (74\% vs. $37 \%$, $P=0.0008)$, mediastinal $(62 \%$ vs. $29 \%, P=0.002)$ or bone marrow $(47 \%$ vs. $19 \%, P=0.004)$ involvement and presence of effusions $(36 \%$ vs. $2 \%, P=0.0009)$. They had also higher aaIPI (75\% vs. $17 \%, P<0.0001)$. Finally, they exhibited lower $\mathrm{Hb}$ levels $(12 \pm 2.4$ vs. $14 \pm 1.9 \mathrm{~g} / \mathrm{dL}, \quad P=0.002)$, higher CRP $(58 \pm 83$ vs. $21 \pm 33 \mathrm{mg} / \mathrm{L}, P=0.0003), \mathrm{LDH}(900 \pm 883$ vs. $500 \pm$ $530 \mathrm{UI} / \mathrm{L}, P<0.0001)$ and $\beta 2$-microglobulin $(4.1 \pm 2.7$ vs. $2.2 \pm 1.3 \mathrm{mg} / \mathrm{L}, P<0.0001)$ levels. 
Table 1 Patient's characteristics* according to histology and for the total population

\begin{tabular}{|c|c|c|c|c|}
\hline \multirow[b]{2}{*}{ Variable } & \multicolumn{2}{|c|}{ Non-Hodgkin's lymphoma } & \multirow[b]{2}{*}{$\begin{array}{l}\text { Hodgkin's disease } \\
(n=21)\end{array}$} & \multirow[b]{2}{*}{$\begin{array}{l}\text { Total population } \\
(n=99)\end{array}$} \\
\hline & $\begin{array}{l}\text { Indolent lymphoma } \\
(n=27)\end{array}$ & $\begin{array}{l}\text { Aggressive lymphoma } \\
(n=51)\end{array}$ & & \\
\hline \multicolumn{5}{|l|}{ Demography } \\
\hline Age (years) & $\begin{array}{l}59 \pm 13 \\
(58,36-80)\end{array}$ & $\begin{array}{l}64 \pm 14 \\
(65,26-88)\end{array}$ & $\begin{array}{l}37 \pm 18 \\
(32,15-78)\end{array}$ & $\begin{array}{l}57 \pm 18 \\
(58,15-88)\end{array}$ \\
\hline \multicolumn{5}{|l|}{ Sex } \\
\hline Female & 44 & 35 & 57 & 42 \\
\hline Male & 56 & 65 & 43 & 58 \\
\hline \multicolumn{5}{|l|}{ Clinical parameters } \\
\hline \multicolumn{5}{|l|}{ Performance status } \\
\hline $0-1$ & 92 & 77 & 85 & 82 \\
\hline$\geq 2$ & 8 & 23 & 15 & 17 \\
\hline \multicolumn{5}{|l|}{ B symptoms } \\
\hline No & 85 & 80 & 67 & 78 \\
\hline Yes & 15 & 20 & 33 & 22 \\
\hline \multicolumn{5}{|l|}{ Ann Arbor stage } \\
\hline I & 37 & 16 & 14 & 21 \\
\hline II & 3.7 & 16 & 57 & 21 \\
\hline III & 3.7 & 18 & 9.5 & 12 \\
\hline IV & 56 & 51 & 19 & 46 \\
\hline \multicolumn{5}{|l|}{ Sites of tumor } \\
\hline Abdominal & 63 & 53 & 24 & 50 \\
\hline Mediastinal & 22 & 33 & 81 & 40 \\
\hline Bone Marrow & 44 & 26 & 14 & 28 \\
\hline Effusion & 13 & 16 & 9.5 & 14 \\
\hline \multicolumn{5}{|l|}{ aalPI } \\
\hline 0 & 35 & 21 & 48 & 31 \\
\hline 1 & 46 & 27 & 29 & 33 \\
\hline 2 & 15 & 31 & 24 & 25 \\
\hline 3 & 3.9 & 21 & 0 & 12 \\
\hline \multicolumn{5}{|l|}{ Biological parameters } \\
\hline CA125 (UI/mL) & $\begin{array}{l}77 \pm 269 \\
(17,7-1418)\end{array}$ & $\begin{array}{l}147 \pm 471 \\
(30,4-3050)\end{array}$ & $\begin{array}{l}39 \pm 44 \\
(20,9-144)\end{array}$ & $\begin{array}{l}105 \pm 368 \\
(21,4-3050)\end{array}$ \\
\hline$\%$ elevated $\quad(\geq 35 \mathrm{UI} / \mathrm{mL})$ & 19 & 45 & 29 & 34 \\
\hline $\mathrm{Hb}(\mathrm{g} / \mathrm{dL})$ & $\begin{array}{l}14.0 \pm 2.0 \\
(14.4,8.9-18.0)\end{array}$ & $\begin{array}{l}13.1 \pm 2.2 \\
(13.4,7.8-16.9)\end{array}$ & $\begin{array}{l}12.6 \pm 2.3 \\
(12.8,8.5-15.8)\end{array}$ & $\begin{array}{l}13.2 \pm 2.2 \\
(13.5,7.8-18.0)\end{array}$ \\
\hline CRP (mg/L) & $\begin{array}{l}11 \pm 15 \\
(3,2-56)\end{array}$ & $\begin{array}{l}41 \pm 68 \\
(15,1-390)\end{array}$ & $\begin{array}{l}45 \pm 59 \\
(27,2-240)\end{array}$ & $\begin{array}{l}34 \pm 58 \\
(13,1-390)\end{array}$ \\
\hline LDH (UI/L) & $\begin{array}{l}388 \pm 135 \\
(358,185-797)\end{array}$ & $\begin{array}{l}841 \pm 912 \\
(561,296-5028)\end{array}$ & $\begin{array}{l}463 \pm 199 \\
(392,272-1119)\end{array}$ & $\begin{array}{l}635 \pm 692 \\
(431,185-5028)\end{array}$ \\
\hline ß2-microglobulin (mg/L) & $\begin{array}{l}2.7 \pm 1.8 \\
(2.0,1.3-8.9)\end{array}$ & $\begin{array}{l}3.3 \pm 2.4 \\
(2.3,1.0-12.0)\end{array}$ & $\begin{array}{l}2.2 \pm 1.2 \\
(1.8,0.9-5.7)\end{array}$ & $\begin{array}{l}2.9 \pm 2.1 \\
(2.0,0.9-12.0)\end{array}$ \\
\hline
\end{tabular}

$\mathrm{Hb}$, hemoglobin; CRP, C-reactive protein; LDH, lactate deshydrogenase.

* For continuous variables: mean \pm SD (median, range) and for categorical variables: \%.

When the analysis was restricted to patients with indolent lymphomas, those with elevated CA125 serum levels had more often mediastinal involvement $(60 \%$ vs. $14 \%, P=0.042)$, higher aaIPI $(60 \%$ vs. $10 \%, P=$ $0.024)$, higher $\mathrm{LDH}(564 \pm 186$ vs. $348 \pm 82 \mathrm{UI} / \mathrm{L}$, $P=0.022), \quad \mathrm{CRP} \quad(25 \pm 23$ vs. $\quad 7 \pm 10 \mathrm{mg} / \mathrm{L}, \quad P=$ $0.049) \quad$ and $\quad \beta 2$-microglobulin $\quad(5.0 \pm 2.8 \quad$ vs. $2.1 \pm 0.8 \mathrm{mg} / \mathrm{L}, P=0.024)$ levels.

In aggressive NHL, patients with elevated CA125 serum levels had more frequently poor performance status $(40 \%$ vs. $11 \%, P=0.028)$, B symptoms $(41 \%$ vs. $4 \%, P=$ $0.0091)$, advanced clinical stage $(96 \%$ vs. $46 \%, P=$ $0.003)$, abdominal ( $78 \%$ vs. $32 \%, P=0.0017)$, mediastinal $(52 \%$ vs. $18 \%, P=0.013)$ or bone marrow ( $44 \%$ vs. $11 \%, P=0.012)$ involvement, high aaIPI ( $81 \%$ vs. $30 \%$, $P=0.0009)$, low $\mathrm{Hb}(12 \pm 2.5$ vs. $14 \pm 1.7 \mathrm{~g} / \mathrm{dL}, P=$ 0.027), high CRP $(63 \pm 91$ vs. $24 \pm 34 \mathrm{mg} / \mathrm{L}, P=$ $0.043), \mathrm{LDH}(1051 \pm 1045$ vs. $677 \pm 778 \mathrm{UI} / \mathrm{L}, P=$ $0.0081)$ or $\beta 2$-microglobulin $(4.3 \pm 2.9$ vs. $2.5 \pm 1.7 \mathrm{mg}$ / $\mathrm{L}, P=0.0057)$ levels. 
Table 2 Univariate Cox analyses for progression-free and overall survival

\begin{tabular}{|c|c|c|c|c|}
\hline \multirow[b]{2}{*}{ Variable } & \multicolumn{2}{|c|}{ Overall survival } & \multicolumn{2}{|c|}{$\begin{array}{l}\text { Progression-free } \\
\text { survival }\end{array}$} \\
\hline & Hazard ratio & $P$-value & Hazard ratio & $P$-value \\
\hline \multicolumn{5}{|l|}{ Histology } \\
\hline \multicolumn{5}{|l|}{ Lymphoma $^{1}$} \\
\hline Indolent & 0.71 & 0.67 & 2.5 & 0.16 \\
\hline Aggressive & 2.26 & 0.20 & 2.7 & 0.11 \\
\hline \multicolumn{5}{|l|}{ Demography } \\
\hline Age (years) & 1.02 & 0.08 & 1.03 & 0.004 \\
\hline \multicolumn{5}{|l|}{ Sex } \\
\hline Male & 1.09 & 0.85 & 1.6 & 0.19 \\
\hline \multicolumn{5}{|l|}{ Clinical parameters } \\
\hline \multicolumn{5}{|l|}{ Performance status } \\
\hline $2-3$ & 5.1 & 0.0005 & 3.0 & 0.007 \\
\hline \multicolumn{5}{|l|}{ B symptoms } \\
\hline Yes & 4.3 & 0.0014 & 2.3 & 0.031 \\
\hline \multicolumn{5}{|l|}{ Ann Arbor stage } \\
\hline III-IV & 3.3 & 0.033 & 4.6 & 0.0019 \\
\hline \multicolumn{5}{|l|}{ Sites of tumor } \\
\hline Abdominal & 1.7 & 0.23 & 2.8 & 0.0088 \\
\hline Mediastinal & 2.3 & 0.06 & 1.1 & 0.71 \\
\hline Bone marrow & 2.8 & 0.02 & 2.9 & 0.003 \\
\hline Effusion & 1.2 & 0.81 & 1.9 & 0.18 \\
\hline \multicolumn{5}{|l|}{ AalPI } \\
\hline $2-3$ & 5.3 & 0.0006 & 3.9 & 0.0004 \\
\hline \multicolumn{5}{|l|}{ Biological parameters } \\
\hline \multicolumn{5}{|l|}{ CA125 } \\
\hline$\geq 35 \mathrm{UI} / \mathrm{mL}$ & 1.8 & 0.20 & 1.8 & 0.11 \\
\hline $\mathrm{Hb}(\mathrm{g} / \mathrm{dL})^{2}$ & 0.03 & 0.001 & 0.15 & 0.035 \\
\hline $\mathrm{CRP}(\mathrm{mg} / \mathrm{L})^{2}$ & 1.5 & 0.007 & 1.3 & 0.036 \\
\hline $\mathrm{LDH}(\mathrm{UI} / \mathrm{L})^{2}$ & 1.8 & 0.06 & 1.6 & 0.057 \\
\hline$\beta 2-$ microglobulin $(\mathrm{mg} / \mathrm{L})^{2}$ & 5.9 & $<0.0001$ & 4.1 & $<0.0001$ \\
\hline
\end{tabular}

$\mathrm{Hb}$, hemoglobin; CRP, C-reactive protein; LDH, lactate deshydrogenase.

1 Reference $=$ Hodgkin's disease.

2 Log-transformation.

In multivariate analysis adjusted for histological group, only bone marrow involvement $(P=0.032)$, the presence of effusion $(P=0.009)$ and high aaIPI $(P=0.002)$ were significantly associated with high CA125 serum levels.

OS was significantly worse for patients with poor performance status hazard ratio ( $\mathrm{HR}=5.1, P<0.0005)$, B symptoms $(\mathrm{HR}=4.3, \quad P=0.0014)$, advanced clinical stage $(\mathrm{HR}=3.3, P=0.033)$, bone marrow involvement $(\mathrm{HR}=2.8, \quad P=0.02)$, high aaIPI $(\mathrm{HR}=5.3, \quad P=$ 0.0006), low $\mathrm{Hb}(\mathrm{HR}=0.03, P=0.001)$, high $\mathrm{CRP}$ $(\mathrm{HR}=1.5, \quad P=0.007) \quad$ and high $\quad \beta 2$-microglobulin $(\mathrm{HR}=5.9, P<0.0001) \quad($ Table 2 , Fig. 1$)$. Progressionfree survival (PFS) was significantly worse for older patients $(\mathrm{HR}=1.03, P=0.004)$, those with poor performance status $(\mathrm{HR}=3.0, \quad P=0.007), \quad B$ symptoms $(\mathrm{HR}=2.3, P=0.031)$, advanced clinical stage $(\mathrm{HR}=$ 4.6, $P=0.0019)$, abdominal $(\mathrm{HR}=2.8, P=0.009)$ as

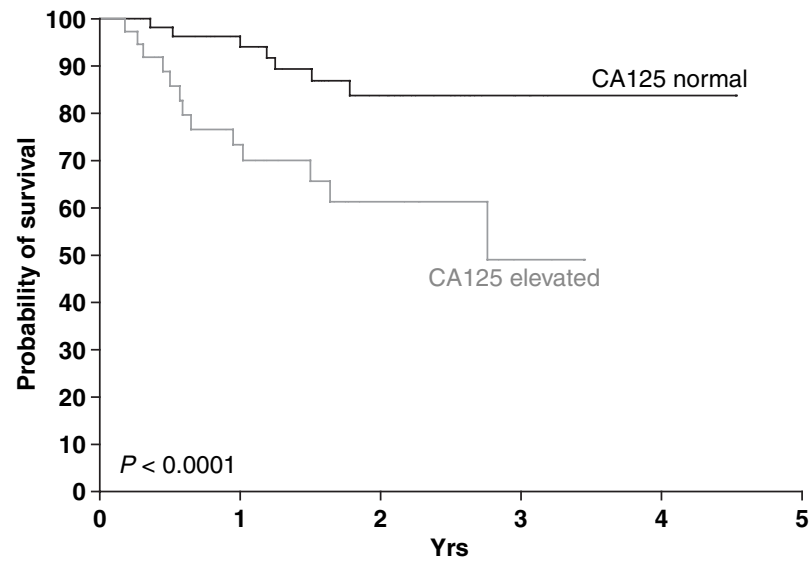

Figure 1 Overall Survival according to $\beta 2$-microglobulin level at diagnosis.

well as bone marrow $(\mathrm{HR}=2.9, P=0.003)$ involvement, high aaIPI $(\mathrm{HR}=3.9, P=0.0004)$, low $\mathrm{Hb}$ $(\mathrm{HR}=0.15, \quad P=0.035)$, high $\mathrm{CRP} \quad(\mathrm{HR}=1.3, \quad P=$ $0.036)$ and high $\beta 2$-microglobulin $\quad(\mathrm{HR}=4.1$, $P<0.0001$ ) (Table 2). OS and PFS were not different in patients with normal or elevated CA125 levels.

In multivariate Cox models, when adjusting for CA125 levels and for histological group, OS and PFS were significantly affected adversely only by high $\beta 2$ microglobulin (OS: HR $=7.1, P<0.0001$; PFS: HR = 5.9, $P<0.0001$ ) (Table 3). For PFS, we also noted a worse outcome for men $(\mathrm{HR}=2.7, P=0.015)$. There was no effect of CA125 levels (OS, $P=0.18$; PFS, $P=$ $0.48)$ and no difference between histological groups (OS: $P>0.5$; PFS: $P>0.5$ ).

\section{Discussion}

In this study, we retrospectively evaluated the significance of CA125 serum levels in 99 patients with lymphoma. We first analyzed the clinical and biological characteristics associated with elevated CA125 levels at diagnosis. High CA125 serum levels were observed in $34 \%$ of the patients. This percentage is comparable with figures previously reported by other authors $(2,5-7,14$ 17). In univariate analysis, many characteristics of more advanced disease were associated with elevated CA125 values. However, in multivariate analysis, an association was only found between high CA125 serum levels, on the one hand, and the presence of effusions, marrow involvement and high aaIPI, on the other. These results have been previously found by others $(1,2,4-10,17)$.

It is now proven that it is not the malignant lymphocytes but mesothelial cells that produce CA125 $(1,4,5$, 10, 14). Inflammatory cytokines, such as IL-1 and TNF$\alpha$, produced by macrophages and lymphoma cells, are 
Table 3 Multivariate Cox analyses (adjusted for histology and CA125 level) for progressionfree and overall survival

\begin{tabular}{|c|c|c|c|c|c|c|}
\hline \multirow[b]{2}{*}{ Variable } & \multicolumn{3}{|c|}{ Overall survival } & \multicolumn{3}{|c|}{ Progression-free survival } \\
\hline & $P$-value & Hazard ratio & $95 \% \mathrm{Cl}$ & $P$-value & Hazard ratio & $95 \% \mathrm{Cl}$ \\
\hline \multicolumn{7}{|l|}{ Lymphoma $^{1}$} \\
\hline Indolent & 0.8336 & 0.82 & $0.13-5.00$ & 0.0972 & 3.74 & $0.79-17.76$ \\
\hline Aggressive & 0.3871 & 1.95 & $0.43-8.89$ & 0.1417 & 3.12 & $0.68-14.23$ \\
\hline CA125 (UI/L) & 0.1795 & 0.48 & $0.16-1.40$ & 0.4772 & 0.70 & $0.27-1.86$ \\
\hline$\beta 2-$ microglobulin (mg/L) & $<0.0001$ & 7.13 & $2.82-18.01$ & $<0.0001$ & 5.93 & $2.58-13.60$ \\
\hline Male sex & - & - & - & 0.0146 & 2.72 & $1.22-6.06$ \\
\hline
\end{tabular}

${ }^{1}$ Reference $=$ Hodgkin's disease. suspected to stimulate CA125 $(1,4,14)$, but also IL-6 and IL-8 production $(5,15)$. The presence of effusion or the involvement of serous membranes (such as the peritoneum, pericardium or pleura) can thus enhance CA125 production by mesothelial cells $(1,2)$. Because of CA125 production by cells other than lymphoma cells, its serum levels are more a reflection of the inflammatory response to the disease than of the tumor mass itself. As cytokine production is proportional to the tumor mass (15), it is not surprising that CA125 are mostly found in association with various characteristics of advanced disease.

We now have good prognostic factors, such as the aaIPI (3) for aggressive NHL and the FLIPI (18) for follicular lymphoma. Given the association of CA125 levels with higher aaIPI, the gold standard of prognostic evaluation of lymphoma patients, one could predict that CA125 levels would not enhance that prognostic assessment. Indeed, CA125 serum levels did not improve its performance in our study. It would therefore be inappropriate to take therapeutic decisions based on CA125 serum levels.

Some authors have reported worse outcome in patients with high CA125 levels $(1,4,7,8)$. In univariate analysis, Bairey et al. (4) found significantly worse OS in patients with aggressive NHL and elevated CA125 but this biological factor lost its prognostic significance in multivariate analysis. Zacharos et al. (1) observed 5-yr survival of $65 \%$ vs. $20 \%$ in patients with aggressive NHL and normal or elevated CA125, respectively. This difference remained significant in multivariate analysis. Benboubker et al. (7) reported significantly better outcome in patients with low-grade NHL and normal CA125 levels but the results of multivariate analyses are unknown. Finally, in a study of 38 patients, Zidan et al. (6) showed inferior OS for patients with aggressive NHL and high CA125 levels (5-yr OS: $35 \%$ vs. $76 \%$, respectively). This difference remained significant after the population was split into histological subgroups. We were not able to confirm this. In our series, only $\beta 2$-microglobulin worsened PFS or OS. This result has already been reported and is now well validated (15). These contradictory results could be related to different patient populations and treatments, and should be better investigated in multicenter studies including more patients, receiving the same treatment and presenting homogenous histological and clinical features.

The role of CA125 levels in the early detection of relapse in CA125-producing patients has also been reported $(1,2,4,6)$. Perhaps, other methods, such as PET scans or combined CT-PET scans (19), would be more efficient, though more costly but this remains to be prove. However, the decrease of CA125 serum levels during therapy could be an argument for adequate tumor response to therapy in so far as there are no concomitant abdominal, pericardial or pleural abnormalities.

In conclusion, while CA125 serum level correlates with a number of features associated with more aggressive disease, it does not enhance the performance of standard prognostic factors in the treatment of patients with NHL or HD.

\section{References}

1. Zacharos ID, Efstathiou SP, Petreli E, Georgiou G, Tsioulos DI, Mastorantonakis SE, Christakopoulou I, Roussou PP. The prognostic significance of CA 125 in patients with non-Hodgkin's lymphoma. Eur J Haematol 2002;69:221-6.

2. Lazzarino M, Orlandi E, Klersy C, Astori C, Brusamolino E, Corso A, Bellio L, Gargantini L, Morra E, Bernasconi C. Serum CA 125 is of clinical value in the staging and follow-up of patients with non-Hodgkin's lymphoma: correlation with tumor parameters and disease activity. Cancer 1998;82:576-82.

3. The International Non-Hodgkin's Lymphoma Prognostic Factors Project. A predictive model for aggressive nonHodgkin's lymphoma. The International Non-Hodgkin's Lymphoma Prognostic Factors Project. $N$ Engl J Med 1993;329:987-94.

4. Bairey O, Blickstein D, Stark P, Prokocimer M, Nativ HM, Kirgner I, Shaklai M. Serum CA 125 as a prognostic factor in non-Hodgkin's lymphoma. Leuk Lymphoma 2003;44:1733-8.

5. Vlasveld LT, Ermens AAM, Sonnenberg AA, Pauwels P. Elevated serum Ca-125 concentrations due to expression by a diffuse large B-cell lymphoma. Ann Clin Biochem 2000;37:545-8. 
6. Zidan J, Hussein O, Basher W, Zohar S. Serum CA125: a tumor marker for monitoring response to treatment and follow-up in patients with non-Hodgkin's lymphoma.

Oncologist 2004;9:417-21.

7. Benboubker L, Valat C, Linassier C, Cartron G, Delain M, Bout M, Fetissof F, Lafranq T, Lamagnere JP, Colombat P. A new serologic index for low-grade nonHodgkin's lymphoma based on initial CA125 and LDH serum levels. Ann Oncol 2000;11:1485-91.

8. Ravoet C, Dargent JL, Le Moine F, Feremans W. CA-125 in primary mediastinal B-cell lymphoma with sclerosis. J Clin Oncol 1995;13:530-1.

9. Dilek I, Ayakta H, Demir C, Meral C, Ozturk M. CA 125 levels in patients with non-Hodgkin lymphoma and other hematologic malignancies. Clin Lab Haematol 2005;27:51-5.

10. Fehm T, Beck E, Valerius T, Gramatzki M, Jager W. CA 125 elevations in patients with malignant lymphomas. Tumour Biol 1998;19:283-9.

11. Harris NL, Jaffe ES, Stein H, et al. A revised European-American classification of lymphoid neoplasms: a proposal from the International Lymphoma Study Group. Blood 1994;84:1361-92.

12. Schnitzer B. Classification of lymphomas. CRC Crit Rev Clin Lab Sci 1978;9:123-78.
13. Cox DR. Regression model and lifetables. J R Stat Soc 1972;34:187-220.

14. Pabst T, Ludwig C. CA-125: a tumor marker in nonHodgkin's lymphomas? J Clin Oncol 1995;13:1827-8.

15. Morra E. The biological markers of non-Hodgkin's lymphomas: their role in diagnosis, prognostic assessment and therapeutic strategy. Int J Biol Markers 1999;14: 149-53.

16. Kutluk T, Varan A, Erbas B, Buyukpamukcu M. Serum CA 125 levels in children with non-Hodgkin's lymphoma. Pediatr Hematol Oncol 1999;16:311-9.

17. Watanabe M, Kanda T, Takatama M, Iwai T, Naito I, Fukuda T, Hirai S. An autopsy case of malignant lymphoma with a high serum CA 125 level occurring only in the brain and pericardium. $J$ Med 1996;27:221-7.

18. Solal-Celigny $\mathrm{P}$, Roy $\mathrm{P}$, Colombat $\mathrm{P}$, et al. Follicular lymphoma international prognostic index. Blood 2004;104:1258-65.

19. Haioun C, Itti E, Rahmouni A, et al. [18F]fluoro-2-deoxyD-glucose positron emission tomography (FDG-PET) in aggressive lymphoma: an early prognostic tool for predicting patient outcome. Blood 2005;106:1376-81. 